\title{
INFLUIENTTA PREPARATULUI E-SELEN ASUPRA STATUSULUI ANTIOXIDANT LA VACI ÎN PERIOADA DE TRANZIṬIE ȘI LACTAȚIE TIMPURIE
}

\section{Vlasiuc Ion, Cociu Valeriu, Balanescu Savva, Popovici Mihail, Buza Victoria}

Universitatea Agrară de Stat din Moldova, or. Chișinău, Republica Moldova vlasiucion24@gmail.com https://doi.org/10.53937/9789975315975.27

\begin{abstract}
The purpose of the research was to determine and monitor the influence of E-Selen supliment on the antioxidant status of Flecvieh cows during the transition and early lactation period as well as all changes during this period. Determined parameters were GSH-Px; TAC; ROM; MAS. Most significant changes was observed in TAC and GSH-Px. Total antioxidant capacity (TAC) in the plasma during transition period in the experimental group is characterized by an increase in its value, compared to antepartum, and in the control group by a decrease; and maintaining higher values compared to the control group in the postpartum period. Results obtained in the dynamics of (GSH-Px) in plasma, characterized by maintaining a higher level in the experimental group compared to the control group, beginning with 20 days antepartum and ending 30 days $\mathrm{p} / \mathrm{p}$. Balance of antioxidant status during the transition and onset of lactation is of major importance for the state of metabolic health in highly productive milk cows. Administration of the E-Selen supplement to cows, 30 days before parturition, had an influence on antioxidant status indices, expressed by maintaining their positive dynamics compared to control group.
\end{abstract}

Key words: Cattle, E-selenium, selenium, glutathione peroxidase, reactive oxygen metabolites.

\section{INTRODUCERE}

După cum se cunoaște, în organismele aerobe are loc formarea așa numitor metaboliții reactivi ai oxigenului (MRO). În cea mai mare parte această grupă este formată din radicali liberi, dar cuprinde și alte molecule, precum peroxidul de hidrogen. Radicalii liberi pot fi definiți ca molecule sau fragmente moleculare care conțin unul sau mai mulți electroni impari pe orbitele atomice sau moleculare [6]. Una dintre moleculele re- 
dicalice este anionul superoxid, care apare fie prin procese metabolice, fie după activarea oxigenului prin iradiere fizică. Acesta este considerat $\mathrm{MRO}$ «primar» și poate interacționa în continuare cu alte molecule pentru a genera MRO «secundari», predominant prin procese enzimatice, sau direct în urma catalizării unor metale [10].

Seleniul (Se) este un element important în sistemul antioxidant al oricarui organism. În cantități considerabile seleniul se afla în structura enzimei cu proprietăți antioxidante - glutation peroxidaza (GPx). Fiind o enzimă cu activitate antioxidativă contribuie la reducerea efectivă a mai multor molecule cu potențial prooxidativ, precum de $\mathrm{H}_{2} \mathrm{O}_{2}$ în faza apoasă și peroxizii lipidici, respectiv în faza lipidică. Au fost identificate și caracterizate patru izoforme ale GPx-zei: GPx-1 (GPx celular) este omniprezent și reduce $\mathrm{H}_{2} \mathrm{O}_{2}$ și peroxizii acizilor grași [4].

Ar trebui să fie remarcat că vitamina E este unul dintre factorii care influențează consumul de seleniu alimentar, funcțiile antioxidante ale seleniului și vitaminei E sunt interdependente. Conform lui [7], rațiile bogate în carbohidrați, nitrați, sulfați, calciu sau cianura de hidrogen (trifoi, semințe de in) influențează negativ utilizarea de către organism a seleniului la bovine. Sulful (S) ar putea reduce absorbția seleniului prin competitivitatea sterică la o concentrație peste 2,4 g / kg SU. În mod similar, $\mathrm{Fe}^{3+}$ scade rata de absorbție a seleniului, precipitând seleniul până la o formă complexă inabsorbabilă de către enterocite. Un nivel de calciu de 0,8\% din SU în hrană permite o absorbție optimă aparentă a seleniului la vacile de lapte la sfârșitul sarcinii.

Conținutul seleniului în rație ar trebui să se bazeze pe rata eficienței privind evitarea accidentelor datorate deficienței sau excesului. Potrivit lui [3], semnele de toxicitate ale seleniului încep să apară de la 5 la 8 mg în raport la kg de substanță uscată. Cele mai frecvente forme de selenoză este selenoza cronică, denumită boală alcalină, și selenoză acută, cunoscută în mod obișnuit ca boala mușchiului alb [12]. La rândul său, au fost constatate deficiențe marcate când un conținut de seleniu este 
mai mic de 0,05 mg / kg SU într-o dietă [3]. Conținutul maxim de seleniu standard în alimente este stabilit la $300 \mu \mathrm{g} / \mathrm{kg}$ SU în America și $500 \mu \mathrm{g}$ / kg SU în Europa [8]. Cantitatea de seleniu din lapte este influențată de conținutul de seleniu în alimente în funcție de sezon și de regiunea agricolă [9]. Într-un studiu realizat în timpul sezonului de pășunat [1], a raportat un nivel marginal de seleniu în laptele de 14\% din efectivul de lapte. Această observație a fost legată în principal la un aport inadecvat de seleniu din cauza furajelor săraci. Studiile efectuate în Belgia, Coreea de Sud, Grecia și Australia au raportat conținutul de seleniu de 30, 60, 15 și $22 \mu \mathrm{g} / \mathrm{kg}$ în lapte, respectiv [9]. În plus, seleniul prezent în lapte ajută la satisfacerea unei concentrații zilnice de seleniu din lapte la oameni. De exemplu, în Belgia, 4\% din consumul de seleniu de către populație provine din lapte și derivatele acestuia iar în Coreea de Sud, această rată crește la 7\% [11].

Valorile ridicate ale GPX și SOD în a doua și, respectiv, în a treia săptămână pot fi interpretate ca un efort al organismului de a se adapta la un nivel ridicat de producție ROS. Același model al modificării activității enzimatice a fost observat pentru catalaza sanguină [2].

\section{MATERIALE ȘI METODE}

Cercetările au fost efectuate în perioada iulie-decembrie 2017, la ferma didactică de bovine a UASM. La fermă sunt înreținute treizeci de vaci de rasa Fleckvieh (de genetică Simmental) cu originea din Germania, aflându-se în cea de a doua și a treia gestație. Vacile sunt întreținute în stabulație liberă, iar de 3-4 ori pe săptămână sunt scoase la plimbare în aer liber într-un padoc amenajat în apropiere. Cercetările s-au efectuat pe 11 vaci, aflate în a doua gestație, selectate cu 30-35 zile înainte de parturiție. Monitorizarea acestora a început în luna iulie și s-a încheiat în luna decembrie, cuprinzând astfel perioada de repaus mamar și primele două luni de lactație ale fiecăreia în parte.

În vederea aprecierii acțiunii unui produs care conține antioxidanții, 
vitamina E și Seleniu animalele au fost divizate în două loturi, dintre care primul - lotul martor, în care au fost incluse șase vaci și, al doilea - lotul experimental, care a cuprins alte cinci bovine. Conform schemei experienței (tab. 1), vacilor din lotul II (experimental) li s-a administrat intramuscular preparatul injectabil "E-Selen" produs al companiei "NITA-FARM", conform instrucțiunii, cu 30 zile înainte de data presupusei fătări.

Tabelul 1. Schema cercetărilor privind utilizarea preperatului E-Selen la vaci

\begin{tabular}{|c|c|c|c|c|}
\hline Lot & Nr. animale & $\begin{array}{l}\text { Preparatul } \\
\text { "E-Selen" }\end{array}$ & Indicii biochimici & $\begin{array}{l}\text { Prelevare sânge, * } \\
\text { (zile) }\end{array}$ \\
\hline \multirow{3}{*}{ I } & \multirow{3}{*}{6} & \multirow{3}{*}{$\begin{array}{l}\text { nu s-a } \\
\text { administr. }\end{array}$} & \multirow[t]{2}{*}{$\begin{array}{l}\text { Activitatea glutationperoxida- } \\
\text { zei }(\mu \mathrm{mol} / \mathrm{L})\end{array}$} & $20-10 a / p$ \\
\hline & & & & $10-12 p / p$ \\
\hline & & & \multirow{3}{*}{$\begin{array}{l}\text { Masa substanțelor } \\
\text { antioxidante (u.c.) }\end{array}$} & \multirow{2}{*}{$30 \mathrm{p} / \mathrm{p}$} \\
\hline \multirow{3}{*}{$\begin{array}{l}\text { II } \\
\text { (experim.) }\end{array}$} & \multirow{3}{*}{5} & \multirow{3}{*}{$\begin{array}{l}14 \mathrm{ml} \text {, IM, } \\
\text { cu } 30 \text { zile } \\
\text { antepartum }\end{array}$} & & \\
\hline & & & & $45 \mathrm{p} / \mathrm{p}$ \\
\hline & & & $\begin{array}{l}\text { Metaboliții reactivi ai oxigenu- } \\
\text { lui (u.c.) }\end{array}$ & $60 \mathrm{p} / \mathrm{p}$ \\
\hline
\end{tabular}

Legenda: ${ }^{*} a / p$ - ante partum; $\mathrm{p} / \mathrm{p}$ - post partum

Acest medicament a fost selectat datorită proprietaților sale farmacologice. Acestea fiind prin faptul că E-selenul compensează insuficiența vitaminei E și deficiența de seleniu în organismul animal. Vitamina $E$ reglează procesele redox și influențează schimbul de carbohidrați, lipide, îmbunătățește efectele vitaminei $A$ și vitaminei $D_{3^{\prime}}$ stimulează sistemul imunitar și rezistența generală. Seleniul ajută la eliminarea substanțelor toxice din organismul animal, îmbunătățind astfel sistemul imunitar.

În aspect cronologic, parturiția la vacile din lotul martor s-a produs în lunile iulie-august, iar la vacile din lotul experimental această perioadă a cuprins lunile august-noiembrie. Vacile din ambele loturi s-au aflat în condiții similare de exploatare și nutriție pe întreaga perioadă de investigație. 
Totodată, trebuie de menționat că nutriția pe tot parcursul cercetărilor nu a fost una optimală, din punct de vedere al echilibrului nutritiv. Din motive obiective, precum lipsa unor sortimente de furaje (șrot de soie, porumb, tărâță, melasă, siloz), începând cu luna iunie și până în luna noiembrie, conținutul rației nu corespundea necesităților prescrise de normele nutriționale.

În conformitate cu schema experienței vacile au fost supravegheate începând cu 30-20 zile înainte de parturiţie și pe parcursul a primelor două luni (60 zile) de lactație. În cadrul cercetărilor s-a urmărit starea generală, prezența apetitului, manifestările de comportament, efectuarea micţiunii și defecării. S-a efectuat evaluarea condiţiei corporale prin inspecție (apreciată la scara de la 1 până la 5 puncte), și s-a urmărit nivelul producției de lapte produs prin efectuarea mulsorilor de control.

Prelevarea probelor de sînge a fost efectuată din vena jugulară ( $v$. Jugularis) între orele 9-11 dimineața, pentru prelevare au fost utilizate eprubete fără anticoagulant (VACUTEST, Clot Activator; de $6 \mathrm{ml}$ ) pentru obținerea serului. După coagularea probelor de sânge la temperatura camerei serul a fost separat prin centrifugare la $3000 \mathrm{rot} / \mathrm{min}$, timp de 20 min și transferat în eprubete Ependorf. Până la efectuarea analizelor biochimice probele de ser au fost păstrate în stare de congelare la temperatura de $-18^{\circ} \mathrm{C}$.

\section{REZULTATE ȘI DISCUŢII}

În probele de ser obținute în cele cinci reprize s-au determinat următorii parametri biochimici: activitatea glutation peroxidazei (GPX), capacitatea antioxidantă totală (CAT), masa substanțelor antioxidante (MSA) și metaboliții reactivi ai oxigenului (MRO). Determinarea acestor indici biochimici s-a realizat în laboratorul de biochimie al Universității de Stat de Medicină și Farmacie "N. Testemițanu", conform metodelor descrise de Gudumac V. și al., 2012.

În urma cercetărilor de laborator și determinării CAT au fost obținute rezultate, pozitive. Acestea însă fiind nesemnificative din aspect statistic. 
Poate fi observat că la lotul experimental în perioada ante-partum (20-10 zile) capacitatea antioxidantă totală (CAT) are o valoare mai mică față de lotul martor (5,8 \%). Situația se modifică în perioada post-partum, unde are loc scăderea CAT in perioada 10-30 zile p/p la lotul martor. În aceeași perioadă la lotul experimental se observă o creștere ușoară cu $+4,6 \%$ pentru 10-14 zile p/p; $+8,4 \%$ pentru 30 zile p/p. După care începe o stabilizare a CAT la ambele loturi și egalarea valorilor atît la lotul martor cît și experimental (tab. 2).

Luând în considerare rezultatele obținute se poate menționa că CAT la lotul martor scade în perioada postpartum deoarece are loc intensificarea metabolismului și creșterea necesității în antioxidanți, dar posibil și prin transmiterea substanțelor antioxidante către făt. Spre deosebire de martor, la vacile din lotul experimental dinamica acestui parametru (CAT) este pozitivă și se datorează, cel mai probabil, efectului administrării preparatului E-Selen.

Tabelul 2. Dinamica capacității antioxidante totale și activității GSH-Px în plasmă la vaci

\begin{tabular}{|l|l|l|l|l|l|l|}
\hline \multirow{2}{*}{ Indicii } & \multirow{4}{*}{ Lotul } & \multicolumn{4}{|l|}{ Perioada de cercetare } \\
\cline { 2 - 8 } & $20-10 \mathrm{a} / \mathrm{p}$ & $10-14 \mathrm{p} / \mathrm{p}$ & $30 \mathrm{p} / \mathrm{p}$ & $45 \mathrm{p} / \mathrm{p}$ & $60 \mathrm{p} / \mathrm{p}$ \\
\hline $\begin{array}{l}\text { Capacitatea } \\
\text { antioxidantă } \\
\text { totală } \\
(\mathrm{u} / \mathrm{c})\end{array}$ & Martor & $30,47 \pm 2,75$ & $29,71 \pm 6,51$ & $28,86 \pm 1,66$ & $30,51 \pm 4,39$ & $29,80 \pm 3,27$ \\
\cline { 2 - 8 } & E-Se & $28,79 \pm 1,93$ & $31,10 \pm 2,57$ & $31,31 \pm 2,31$ & $30,03 \pm 2,45$ & $29,91 \pm 2,89$ \\
\hline $\begin{array}{l}\text { Glutation } \\
\text { peroxidaza } \\
(\mu \text { mol/L) }\end{array}$ & Martor & $544,6 \pm 121,9$ & $481,4 \pm 152,7$ & $522,5 \pm 160,5$ & $529,0 \pm 135,4$ & $413,8 \pm 96,8$ \\
\cline { 2 - 8 } & E-Se & $645,8 \pm 114,6$ & $664,7 \pm 168,6$ & $633,6 \pm 203,9$ & $398,0 \pm 88,9$ & $437,5 \pm 102,2$ \\
\hline
\end{tabular}

În privința activității glutation peroxidazei (GPx) sa constatat un nivel ridicat față de lotul martor, acesta fiind de 645,82 $\mu \mathrm{mol} / \mathrm{L}$ cu o descrestere usoară pînă la 633,63 mol/L în perioada de la 20-10 zile a/p pînă la 
30 zile p/p. Putem spune că nivelul GPx la lotul experimental se menținea stabil de la momentul injectării E-Selen, adică 30 ziel antipartum și pînă în perioda 30 zile p/p și 45 zile p/p, după care concentrația de GPx se stabilește la un nivel aproape egal cu lotul martor în aceeași perioada. Diferența cea mai vizibilă între cele doua grupe este între perioada 2010 zile a/p și 30-45 zile p/p: 16,9 \% în perioada 20-10 zile a/p; 31,9 \% în perioada 10-14 zile $p / p ; 19,2 \%$ în perioada 30 zile p/p.

În cercetările efectuate de către Fiștilă l. et al. (2012) pe tematica stresului oxidativ si nivelul de glutation peroxidază în dependență de diferite faze fiziologice (gestație avansată; lactație timpurie zile; perioada de lactație desfașurată 25-35 zile postpartum), au obținut rezultate apropiate cu rezultatele lotului martor din cercetarea noastă.

Dinamică pozitivă sa observat și la indici MRO și MSA. În perioada înainte de fătare (20-10 zile a/p) sa constatat conținut mai mare de MRO la vacile din lotul martor. După care, în perioada post partum, nivelul de MRO începe să scadă și să ajungă la valoarea de 5,39 u/c (30 zile p/p). La lotul experimental nivelul de MRO se menține la nivel mai scăzut comparativ cu lotul martor pe parcursul întregii perioade de cercetare (20-10 zile a/p pînă la 60 zile p/p).Diferența dintre nivelul MRO la lotul experimental și lotul martor este maximală în perioada 21-10 zile a/p constituind $46,9 \%$. Luând în considerare cercetările efectuate de către U. Bernabucci et al. (2005) care au obținut rezultate diferite, acestea fiind exprimate prin majorarea statusului MRO în perioada 0-30 p/p, putem spune că oscilările ce apar în MRO sunt dependente de perioada fiziologică și intensitatea stresului oxidativ.

Masa substanțelor antioxidante (MSA) vin în corelație cu MRO, având o dinamică direct proporționali. În rezultatele obținute este observat faptul ca nu sunt produse modificări majore vizibile la lotul experimental față de lotul martor. Însă totuși se urmărește o creștere ușoara a MSA în perioada 10-14 zile p/p și 60 zile p/p la vacile sa injectat E-Selen (tab. 3). 
Tabelul 3. Dinamica metaboliților reactivi ai oxigenului și masei substanțelor antioxidante în plasmă la vaci

\begin{tabular}{|l|l|l|l|l|l|l|}
\hline \multirow{2}{*}{ Indicii } & \multirow{5}{*}{ Lotul } & \multicolumn{5}{|l|}{ Perioada de cercetare } \\
\cline { 3 - 7 } & $20-10 \mathrm{a} / \mathrm{p}$ & $10-14 \mathrm{p} / \mathrm{p}$ & $30 \mathrm{p} / \mathrm{p}$ & $45 \mathrm{p} / \mathrm{p}$ & $60 \mathrm{p} / \mathrm{p}$ \\
\hline $\begin{array}{l}\text { Masa substan- } \\
\text { țelor } \\
\text { antioxidante } \\
\text { (u/c) }\end{array}$ & Martor & $2,21 \pm 0,01$ & $2,21 \pm 0,02$ & $2,22 \pm 0,01$ & $2,22 \pm 0,01$ & $2,22 \pm 0,01$ \\
\cline { 2 - 7 } & E-Se & $2,22 \pm 0,01$ & $2,23 \pm 0,01$ & $2,23 \pm 0,01$ & $2,23 \pm 0,01$ & $2,23 \pm 0,01$ \\
\hline $\begin{array}{l}\text { Metaboliții } \\
\text { reactivi } \\
\text { de oxigen } \\
\text { (u/c) }\end{array}$ & Martor & $8,07 \pm 2,43$ & $6,74 \pm 1,21$ & $5,39 \pm 0,78$ & $5,61 \pm 0,39$ & $5,22 \pm 1,04$ \\
\cline { 2 - 7 } & E-Se & $5,00 \pm 0,43$ & $5,10 \pm 0,86$ & $4,57 \pm 0,95$ & $5,40 \pm 0,16$ & $4,71 \pm 0,65$ \\
\hline
\end{tabular}

Nu putem spune cu certitudine că preparatul E-selen a avut un efect semnificativ, totuși sunt observate modificări pozitive la lotul experimental față de cel martor. Presupunem totuși că preparatul E-Selen a avut o influență pozitivă mai cu seamă în perioada post partum.

\section{CONCLUZII}

Administrarea preparatului E-Selen, la vaci cu 30 zile înainte de parturiție a avut influență pozitivă asupra indicilor statusului antioxidant monitorizați, exprimată prin:

- creșterea valorii capacității antioxidante totale (CAT) față de nivelul antepartum;

- menținerea unui nivel mai înalt al activității glutation peroxidazei (GPx), comparativ cu cel martor;

- tendința de menținere a unui nivel mai înalt al masei substanțelor antioxidante (MSA) și a unui nivel relativ mai scăzut al metaboliților reactivi ai oxigenului (MRO), comparativ cu lotul martor.

Acknowledgement: The study was supported by the Grant Agency for Research and Science, project registration no.: 07/2017-2, established by Czech development project "Modernization and improvement of education and research at State Agrarian University of Moldova". 


\section{BIBLIOGRAFIE}

1. Ceballos-Marquez, A.; Barkema, H.W.; Stryhn, H.; Dohoo, I.R.; Keefe, G.P.; Wichtel, J.J. Milk selenium concentration and its association with udder health in Atlantic Canadian dairy herds. J. Dairy Sci. 2010, 93, 4700-4709. Molecules 2016, 21, 54511 of 14

2. Chan, J. C., J. C. Cheung, C. D. Stchouwer, J. J. Emeis, P. C. Tong, G. T. Ko, and J. S. Yudkin. 2002. The central role of obesity associated dyslipidaemia, endothelial activation and cytokines in the metabolic syndrome An analysis by structural equation modeling. Int. J. Obes. Relat. Metab. Disord. 26:994-1008.

3. Claude, J.B. Introduction à la Nutrition des Animaux Domestiques; Tec \& Doc/ EM Inter: Paris, France, 2002.

4. Fatiha Tabet, Rhian M. Touyz, in Comprehensive Hypertension, 2007, 337.

5. Gudumac V., Rîvneac V., Tagadiuc O., Sardari V. et al. Metode de cercetare a metabolismului hepatic. Elaborare metodică. Sub red. Gudumac V. USMF "Nicolae Testemiţanu". Chișinău, 2012. Tipogr. „Tehnica-Info", 162 P.

6. Halliwell, B., \& Gutteridge, J. M. C. (1999). Free radicals in biology and medicine (3rd ed.). Oxford University Press.

7. Kessler, J. Carence en sélénium chez les ruminants: Mesures prophylactiques. Rev. Suisse Agric. 1993, 25, 21-26.

8. Meschy, F. Nutrition Minérale des Ruminants; Editions Quae: Versaille, France, 2010; p. 208.

9. Tinggi, U.; Patterson, C.; Reilly, C. Selenium levels in cow's milk from different regions of Australia. Int. J. Food Sci. Nutr. 2001, 52, 43-51.

10. Valko, M.,Morris, H., \& Cronin, M. T. D. (2005). Metals, toxicity and oxidative stress. Curr. Med. Chem., 12, 1161-1208.

11. Waegeneers, N.; Thiry, C.; De Temmerman, L.; Ruttens, A. Predicted dietary intake of selenium by the general adult population in Belgium. Food Addit. Contam. A Chem. Anal. Control Expo Risk Assess. 2013, 30, 278-285.

12. Żarczyńska, K.; Sobiech, P.; Radwin’ska, J.; Re_kawek, W. Effects of selenium on animal health. J. Elemntol. 2013, 18, 329-340. 